\title{
Publisher Correction: Metallofullerenes: Welcome to the single-molecule electret device
}

Sadafumi Nishihara (iD)

Correction to: Nature Nanotechnology https://doi.org/10.1038/s41565-020-00780-5, published online 12 October 2020.

In the version of this News \& Views article originally published online, ref. 7 "Reed, A. M. et al. Nat. Nanotechnol. https://doi.org/10.1038/ s41565-020-00780-5 (2020)." was incorrect; it should have been “Zhang, K. et al. Nat. Nanotechnol. https://doi.org/10.1038/s41565-02000778-z (2020)." This has now been corrected in all versions of the News \& Views article.

Published online: 23 October 2020

https://doi.org/10.1038/s41565-020-00801-3

๑) Springer Nature Limited 2020

\section{Publisher Correction: Multifunctional nanocoated membranes for high-rate electrothermal desalination of hypersaline waters}

Kuichang Zuo (D), Weipeng Wang, Akshay Deshmukh (D), Shuai Jia, Hua Guo, Ruikun Xin, Menachem Elimelech (D),

Pulickel M. Ajayan (D), Jun Lou (D) and Qilin Li (D)

Correction to: Nature Nanotechnology https://doi.org/10.1038/s41565-020-00777-0, published online 26 October 2020.

In the version of this Article originally published online, the units in the $y$-axis labels in Fig. $2 \mathrm{~g}$ and the inset of Fig. $2 \mathrm{~g}$ were incorrect; ' $\mathrm{pA}$ ' should have been ' $\mu \mathrm{A}$ ' (main figure) and ' $\mu \mathrm{A}$ ' should have been ' $\mathrm{pA}$ ' (inset figure). This has now been corrected in all versions of the Article.

Published online: 4 November 2020

https://doi.org/10.1038/s41565-020-00806-y

๑) The Author(s), under exclusive licence to Springer Nature Limited 2020 